Case Report

\title{
Successful Modified Therapy in a Patient with Probable Infection-Associated Hemophagocytic Lymphohistiocytosis
}

\author{
Carl L. Kay $\mathbb{D}^{1},{ }^{1}$ Matthew J. Rendo, ${ }^{1}$ Paul Gonzales $\mathbb{D},{ }^{1}$ Sead G. Beganovic, ${ }^{2}$ \\ and Magdalena Czader ${ }^{3}$ \\ ${ }^{1}$ Brooke Army Medical Center, Ft. Sam Houston, TX, USA \\ ${ }^{2}$ Hematology-Oncology, Indiana University School of Medicine, Indianapolis, IN, USA \\ ${ }^{3}$ Hematopathology, Indiana University School of Medicine, Indianapolis, IN, USA \\ Correspondence should be addressed to Carl L. Kay; carl.l.kay.mil@mail.mil
}

Received 23 January 2019; Revised 2 July 2019; Accepted 27 August 2019; Published 8 September 2019

Academic Editor: Raffaele Palmirotta

Copyright (c) 2019 Carl L. Kay et al. This is an open access article distributed under the Creative Commons Attribution License, which permits unrestricted use, distribution, and reproduction in any medium, provided the original work is properly cited.

\begin{abstract}
Hemophagocytic lymphohistiocytosis (HLH) is a rare, hyperinflammatory syndrome characterized by clinical signs and symptoms of extreme inflammation. In adults, HLH is typically a complication of infections, autoimmune diseases, and malignancies. While the disease is often fatal, classic management of HLH revolves around early diagnosis and initiation of protocolized therapy. We present a case of a previously healthy 56-year-old female who developed distributive shock requiring intubation, vasopressors, and continuous venovenous hemofiltration. In the setting of multiple infectious syndromes, severe cytopenias, and rising direct hyperbilirubinemia, her diagnosis of HLH was confirmed. Therapy was initiated with dexamethasone and two doses of reducedintensity etoposide based on the patient's clinical course. Over the next few weeks, she continued to improve on dexamethasone monotherapy and has maintained remission up to the present with complete resolution of her cytopenias and return of baseline renal function. Our case highlights the variability in the management of probable infection-associated HLH (IHLH) with a good patient outcome. We demonstrate the potential to treat IHLH with partial protocols and minimal chemotherapeutics.
\end{abstract}

\section{Introduction}

Hemophagocytic lymphohistiocytosis (HLH) is a rare, hyperinflammatory syndrome characterized by clinical signs and symptoms of extreme inflammation [1]. There are revised criteria for establishing the diagnosis of HLH from the Histiocyte Society based upon the clinical, laboratory, and histopathologic findings (Table 1). HLH is not a single disease but instead represents a collection of disease processes with a similar endstage phenotype [2]. HLH has been described as a primary disorder (i.e., familial or genetic HLH) and also secondary to other disease processes. While both forms of HLH are associated with high morbidity and mortality, secondary HLH occurs in the setting of infectious, malignant, rheumatologic, or metabolic conditions [3]. Occasionally, an inciting trigger is not identified and HLH is considered idiopathic [4].

We will present a case of septic shock with subsequently diagnosed HLH treated successfully without conventional therapy. We provide an overview of the clinical presentation, hospital timeline, and antimicrobial therapy in Tables 2-5 and Figures 1-4.

\section{Case Presentation}

A 56-year-old African American female with no significant past medical history presented with one week of fatigue, nausea, vomiting, diarrhea, intermittent abdominal pain, and subjective fever. Laboratory investigation revealed a serum creatinine of $2.7 \mathrm{mg} / \mathrm{dL}$ with baseline creatinine of $0.8 \mathrm{mg} / \mathrm{dL}$. Renal ultrasound was normal without evidence of obstruction. Computed tomography of the abdomen and pelvis was negative for acute intraabdominal pathology. She was admitted for supportive care and volume repletion for acute renal insufficiency.

Three days after admission, her gastrointestinal symptoms abated, but she developed a productive cough and 
TABle 1: Diagnostic criteria for HLH*.

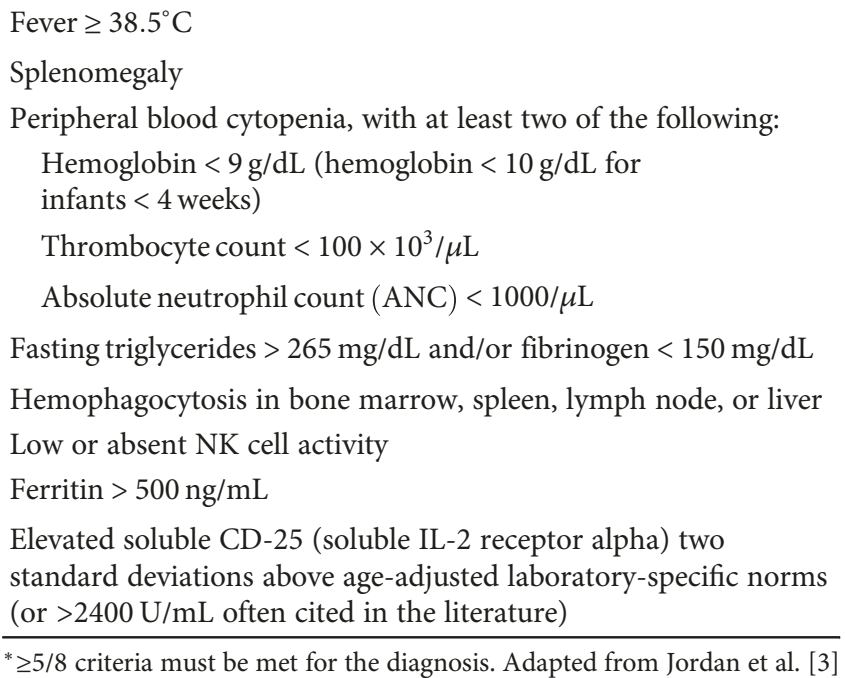

TABLE 2: HLH diagnostic criteria and patient's presentation.

\begin{tabular}{lc}
\hline HLH-2004 diagnostic criteria & \\
\hline Fever & + \\
Splenomegaly & + \\
Cytopenia of $\geq 2$ cell lines & + \\
Triglyceride $\geq 254 \mathrm{mg} / \mathrm{dL}$ & + \\
Fribrinogen $\leq 150 \mathrm{mg} / \mathrm{dL}$ & - \\
Histiocytic hemophagocytosis & + \\
NK cell activity & Normal \\
Ferritin $>500 \mathrm{ng} / \mathrm{mL}$ & $+(2,455 \mathrm{ng} / \mathrm{mL})$ \\
Elevated soluble CD-25 & $+(2,661 \mathrm{U} / \mathrm{mL})$ \\
\hline
\end{tabular}

leukocytosis. Chest X-ray showed increased interstitial markings consistent with atypical pneumonia versus interstitial edema, and she was started on antibiotics. She continued to worsen clinically developing fevers, tachypnea, hypotension, and atrial fibrillation with rapid ventricular response.

She had negative thromboembolic and viral infectious workups including HIV, Epstein-Barr virus, cytomegalovirus, parvovirus B19, human herpes virus-6, and endemic fungal infections. She met criteria for distributive shock, and antibiotic coverage was broadened. Platelet count dropped from $162 \times 10^{3} / \mu \mathrm{L}$ to $51 \times 10^{3} / \mu \mathrm{L}$ in the setting of progressive respiratory distress requiring intubation, vasopressor support, and continuous venovenous hemofiltration (CVVH).

Thrombocytopenic workup revealed elevated D-dimer, elevated haptoglobin, negative serotonin release assay, no red blood cell fragmentation, and only mildly reduced ADAMTS13 activity. Total bilirubin was $22.3 \mathrm{mg} / \mathrm{dL}$ with direct bilirubin of $18.4 \mathrm{mg} / \mathrm{dL}$. Reimaging of the abdomen and pelvis revealed findings suggestive of acalculus cholecystitis, splenomegaly, and thickened gallbladder wall without obstruction. Hepatobiliary iminodiacetic acid (HIDA)
TABLE 3: Overview of patient with HLH associated with severe sepsis and septic shock.

\begin{tabular}{|c|c|}
\hline \multicolumn{2}{|c|}{ Features consistent with severe sepsis and septic shock } \\
\hline $\begin{array}{l}\text { Systemic inflammatory } \\
\text { response syndrome }\end{array}$ & + \\
\hline Infection & Unidentifiable \\
\hline $\begin{array}{l}\text { Hypotension requiring } \\
\text { vasopressors }\end{array}$ & + \\
\hline $\begin{array}{l}\text { Acute respiratory distress } \\
\text { syndrome requiring } \\
\text { mechanical ventilation }\end{array}$ & - \\
\hline $\begin{array}{l}\text { Acute renal failure requiring } \\
\text { dialysis }\end{array}$ & + \\
\hline Altered mental status & + \\
\hline Lactate $>2 \mathrm{mmol} / \mathrm{L}$ & $+(4.1 \mathrm{mmol} / \mathrm{L})$ \\
\hline Platelet count $<100 \times 10^{3} / \mu \mathrm{L}$ & $+\left(15 \times 10^{3} / \mu \mathrm{L}\right)$ \\
\hline $\begin{array}{l}\text { Disseminated intravascular } \\
\text { coagulation }\end{array}$ & - \\
\hline \multicolumn{2}{|c|}{ Other clinical and laboratory features } \\
\hline Anasarca & - \\
\hline Hepatomegaly & - \\
\hline Peak AST (IU/L) & 174 \\
\hline Peak ALT (IU/L) & 192 \\
\hline Peak LDH (IU/L) & 285 \\
\hline Peak total bilirubin (mg/dL) & 22.3 \\
\hline Peak direct bilirubin (mg/dL) & 18.4 \\
\hline Peak prothrombin time $(\mathrm{s})$ & 26.6 \\
\hline Nadir hemoglobin (g/dL) & 5.7 (on hospital day 20) \\
\hline $\begin{array}{l}\text { Nadir absolute neutrophil } \\
\text { count (cells } / \mathrm{mm}^{3} \text { ) }\end{array}$ & 1,600 (on hospital day 26) \\
\hline Other features & $\begin{array}{l}\text { Pericardial effusion, pneumonia, } \\
\text { acalculus cholecystitis, acute } \\
\text { cholangitis, } \\
\text { abdominal wall abscess } \\
\text { secondary to cholecystostomy tube }\end{array}$ \\
\hline
\end{tabular}

scan was nondiagnostic. Endoscopic retrograde cholangiopancreatography (ERCP) was deferred due to severe thrombocytopenia. A transjugular liver biopsy revealed acute cholangitis, and she received percutaneous cholecystostomy and a course of meropenem.

With ongoing and nondiagnosed cytopenias, bone marrow biopsies were performed. First attempt bone marrow specimens were inadequate for analysis. Eventually specimens revealed macrophages with evidence of hemophagocytosis concerning for HLH. The patient met 7 of 8 criteria for establishing a diagnosis of HLH (fever, splenomegaly, cytopenias of at least two cell lines, hypertriglyceridemia, histiocytic hemophagocytosis, hyperferritinemia, and elevated soluble CD-25).

She was initiated on HLH-94 protocol with dexamethasone and etoposide. Given her significant renal impairment, etoposide was administered twice in the first week at $75 \%$ of the recommended dose (i.e., $40 \mathrm{mg} / \mathrm{m}^{2}$ ) based on a 
TABLE 4: Course of illness.

\begin{tabular}{|c|c|}
\hline Course of illness & \\
\hline Onset of shock & Day 8 \\
\hline Intubated & Day 8 \\
\hline Vasopressor initiation & Day 8 \\
\hline CVVH initiated & Day 11 \\
\hline First bone marrow biopsy & Day 11 \\
\hline $\begin{array}{l}\text { Imaging suggestive of } \\
\text { acalculus cholecystitis }\end{array}$ & Day 14 \\
\hline Percutaneous cholecystostomy & Day 15 \\
\hline $\begin{array}{l}\text { Liver biopsy and second bone } \\
\text { marrow biopsy }\end{array}$ & Day 17 \\
\hline Extubated & Day 18 \\
\hline $\begin{array}{l}\text { Liver biopsy reveals acute } \\
\text { cholangitis }\end{array}$ & Day 19 \\
\hline HLH diagnosis made & Day 22 \\
\hline $\begin{array}{l}\text { Initiation of HLH } \\
\text { dexamethasone therapy }\end{array}$ & Day 22 \\
\hline $\begin{array}{l}\text { Initiation of HLH etoposide } \\
\text { therapy }\end{array}$ & Day 24 \\
\hline Repeat vasopressor initiation & Day 30 \\
\hline CVVH discontinued & Day 44 \\
\hline $\begin{array}{l}\text { Discharged to rehabilitation } \\
\text { facility }\end{array}$ & Day 56 \\
\hline Treatment & $\begin{array}{c}2 \text { doses of etoposide } 40 \mathrm{mg} / \mathrm{m}^{2} \text { and } \\
\text { dexamethasone per HLH-94 }\end{array}$ \\
\hline Outcome & $\begin{array}{l}\text { Complete remission (full recovery of } \\
\text { cytopenias and return to baseline } \\
\text { renal function) }\end{array}$ \\
\hline
\end{tabular}

TABLE 5: Antimicrobial course.

\begin{tabular}{|c|c|}
\hline Antimicrobial & $\begin{array}{l}\text { Day after } \\
\text { admission }\end{array}$ \\
\hline Azithromycin $500 \mathrm{mg}$ oral one-time dose & Day 4 \\
\hline Azithromycin $250 \mathrm{mg}$ oral daily & Day 5 \\
\hline Moxifloxacin $400 \mathrm{mg}$ oral daily & Day 6 \\
\hline $\begin{array}{l}\text { Vancomycin } 1.25 \mathrm{~g} \text { load and } \\
\text { Piperacillin/Tazobactam } 3.375 \text { gm intravenous } \\
\text { every } 8 \text { hours }\end{array}$ & Day 7-Day 11 \\
\hline Azithromycin $500 \mathrm{mg}$ intravenous daily & Day 8-Day 11 \\
\hline Meropenem $1 \mathrm{~g}$ intravenous every 8 hours & Day 12-Day 24 \\
\hline Acyclovir $400 \mathrm{mg}$ oral twice daily & Day 23-Day 34 \\
\hline Discontinuation of all antibiotics & Day 25 \\
\hline Vancomycin $2 \mathrm{~g}$ intravenous one-time dose & Day 30 \\
\hline $\begin{array}{l}\text { Piperacillin/Tazobactam } 3.375 \mathrm{~g} \text { intravenous } \\
\text { every } 12 \text { hours }\end{array}$ & Day 30-Day 36 \\
\hline Acyclovir $200 \mathrm{mg}$ oral twice daily & Day 30-Day 47 \\
\hline Ampicillin $2 \mathrm{~g}$ intravenous daily & Day 37-Day 56 \\
\hline
\end{tabular}

creatinine clearance less than 10 milliliters per minute. At the time of her second week of etoposide administration, the patient decompensated in the setting of an abdominal wall abscess associated with the aforementioned cholecystostomy drain. Continued etoposide protocol was deferred given the patient's immune suppression, dramatically worsened clinical status, and risk for toxicity in the setting of concomitant renal and liver dysfunction. Over the course of the next few weeks, she continued to improve without bleeding complications on dexamethasone monotherapy and supportive platelet and packed red blood cell transfusions.

Dexamethasone therapy was administered intravenously for the five weeks the patient remained hospitalized, then the patient was transitioned to oral dexamethasone for the remaining three weeks of the eight-week taper. She followed up monthly in the hematology/oncology clinic and maintained remission up to the present (14 months after admission) with complete resolution of cytopenias and return of baseline renal function.

\section{Discussion}

Repeatedly, the literature suggests that it is necessary to identify and diagnose HLH early to improve mortality. As a result of attempting to diagnose HLH early, diagnostic criteria have been criticized for their nonspecificity [5]. HLH is believed to be overdiagnosed due to these nonspecific diagnostic criteria [2]. Studies show that $60 \%$ of patients with severe sepsis and thrombocytopenia will demonstrate histiocytic hemophagocytosis [6]. Because these diagnostic features are not uncommon in severe sepsis, this suggests that there is much ambiguity about both the diagnosis and, subsequently, the management.

Given our patient's instability and multiple infectious syndromes, genetic testing for primary HLH was foregone. However, primary HLH was thought to be less likely due to the patient's age, no known familial mutations, and no family history of death of a young family member with unexplained fever [7]. Notably, primary HLH cannot be excluded especially considering literature suggesting that primary HLH is often set off by an infectious, malignant, or rheumatologic trigger $[4,8]$. In the absence of known malignancy or rheumatologic disease, her multiple infectious syndromes were the most likely trigger of her HLH diagnosis.

Core to the uncertainty of infection-associated HLH (IHLH) management, it has previously been postulated that IHLH does not represent a distinct disease at all, but simply lies on the extreme end of the inflammatory spectrum of sepsis [9]. Benign histiocytic proliferation in the setting of infection was first described in 1979 by Risdall et al. [10]. Risdall et al. and other more recent literature have posited that patients do better with supportive care than the more radical and necessary treatment used in familial HLH $[10,11]$. In contradiction to other literature suggesting that patients with IHLH should be treated on an HLH protocol $[6,12]$, we demonstrate the potential to treat IHLH with tailored therapy based on the patient's clinical scenario which may not require full-protocol chemotherapeutic agents for full recovery. 


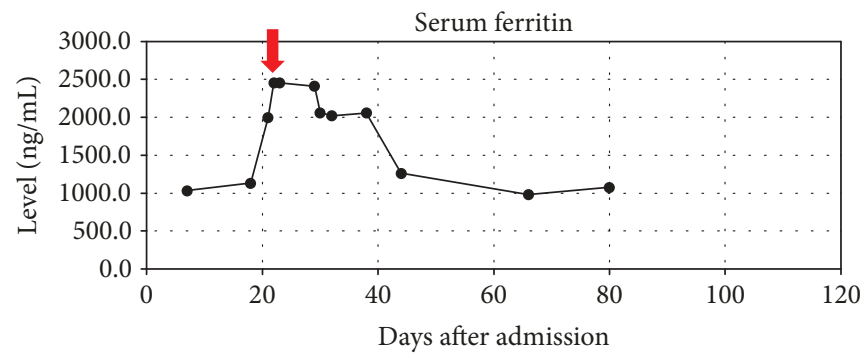

FIgURe 1: Overview of patient ferritin levels with indication of dexamethasone and etoposide initiation.

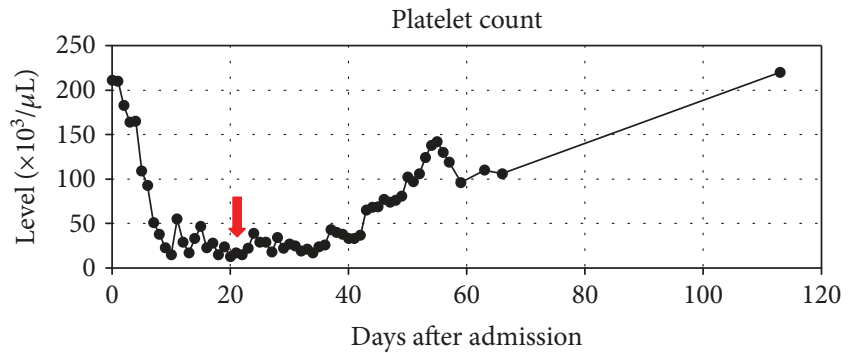

FIGURE 2: Overview of patient platelet count with indication of dexamethasone and etoposide initiation.

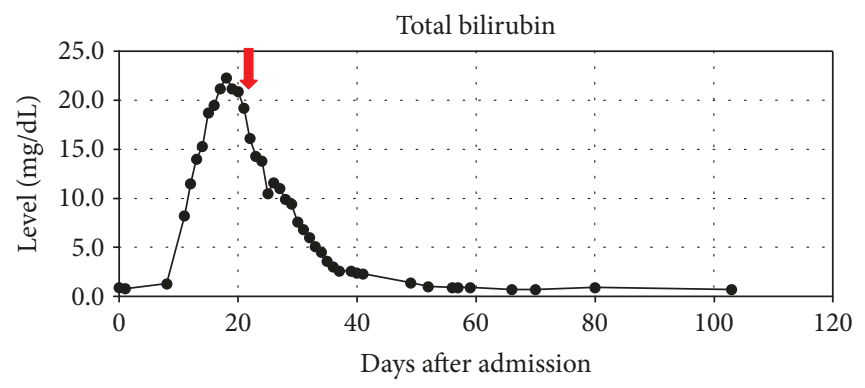

FIGURE 3: Overview of patient total bilirubin levels with indication of dexamethasone and etoposide initiation.

HLH guidelines for diagnosis and therapy are largely based on pediatric patient populations who demonstrated significant mortality benefit while following the therapeutic protocol $[5,13,14]$. Furthermore, the benefits of etoposide have been best described in viral IHLH $[10-12,15]$. However, the literature continues to demonstrate the variability within the disease process, and there have been efforts to refine diagnosis and treatment based upon disease severity $[3,4]$. It would seem that HLH subsets (i.e., adults and nonviral infection-associated HLH) may require therapeutic regimens different from those described in the HLH-94 and HLH-2004 protocols.

Our patient highlights the difficulties of managing such an adult patient with probable nonviral IHLH. There were several factors that made our case particularly challenging: multiple infectious syndromes, acute renal failure increasing the toxicity of etoposide, and delay in diagnosis due to inadequate first bone marrow sampling. Furthermore, our patient was at a very high risk of additional infections and further inflammation as she was immunosuppressed with chemo- therapeutic agents per the HLH protocol. It is not clear that two doses of reduced-intensity etoposide caused clinical deterioration; however, full-protocol etoposide was not necessary for successful treatment. Notably, the continued dexamethasone monotherapy did not result in further deterioration.

While clinical courses and management of HLH vary widely, there are even case reports of HLH patients who improve spontaneously $[16,17]$. Some patients diagnosed with secondary HLH survive with plasma exchange or immune globulin and without chemotherapy [18]. Given the paucity of literature regarding reduced-intensity, monotherapy, or alternative HLH treatment of nonviral IHLH, it is difficult to generalize suggested treatment regimens. However, our case suggests that a modified etoposide regimen may be appropriate in cases when there is clinical deterioration associated with etoposide initiation. Furthermore, dexamethasone monotherapy may be sufficient therapy for successful management in nonviral IHLH. This notion is somewhat contradictory to older observational studies indicating that rapid initiation of etoposide therapy is the 


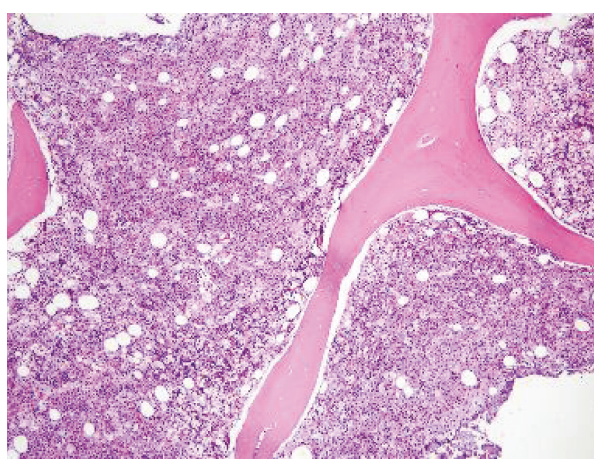

(a)

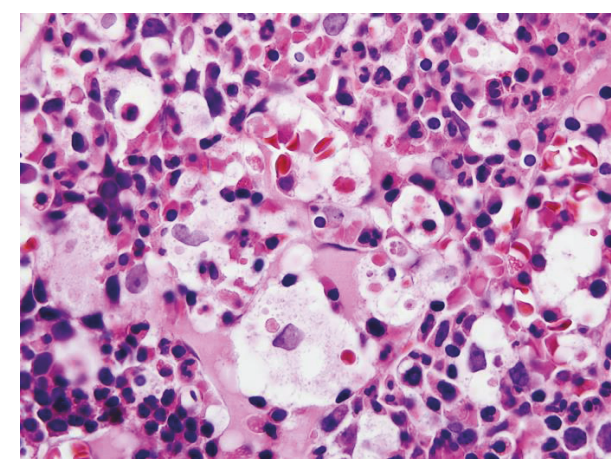

(b)

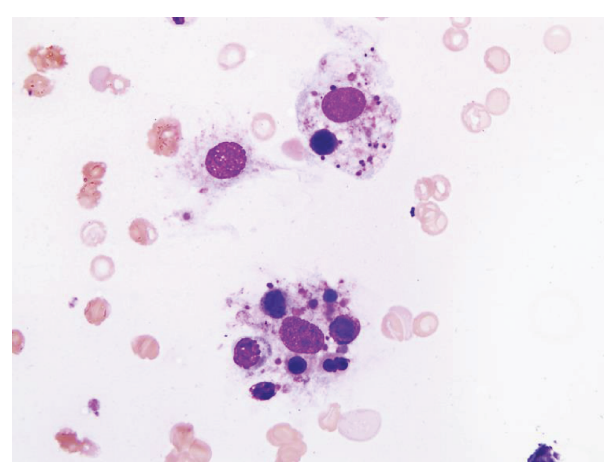

(c)

Figure 4: (a) Markedly hypercellular bone marrow with left-shifted granulopoiesis, increased erythropoiesis with prominent erythroid islands, decreased megakaryopoiesis, and prominent hemophagocytosis (bone marrow biopsy, H\&E, 200x). (b) Clusters of histiocytes with hemophagocytosis (bone marrow biopsy, H\&E, 400x). (c) Bone marrow aspirate was hemodilute; however, it showed focal hemophagocytosis (bone marrow aspirate smear, Wright-Giemsa stain, 1000x).

only factor significantly associated with increased survival in selected adult patients with secondary HLH $[11,15]$. Additionally, not all patients with secondary HLH require prolonged therapy, and, in many cases, treatment can be discontinued once their condition improves and the underlying condition has been treated [2]. The difficulty is identifying when chemotherapeutics are unnecessary and potentially detrimental. Additional reports of modified therapies for nonviral IHLH are needed to provide further guidance and protocols.

Our case highlights the variability in the management of adult IHLH with a good patient outcome. We demonstrate the potential to treat probable IHLH with a modified chemotherapeutic regimen. Given the infectious nature of our case, it would support the notion that IHLH does not represent a distinct disease at all, but IHLH may simply lie on the extreme end of the inflammatory spectrum of sepsis. Further study is needed to protocolize initiation of chemotherapeutics and deescalation of HLH-specific therapy especially in patients at high risk of infections.

\section{Disclosure}

The views expressed herein are those of the authors and do not reflect the official policy or position of Brooke Army Medical Center, the U.S. Army Medical Department, the U.S. Army Office of the Surgeon General, the Department of the Army, the Department of the Air Force, and the Department of Defense or the U.S. Government.

\section{Conflicts of Interest}

The authors declare that they have no conflicts of interest.

\section{References}

[1] M. Campo and N. Berliner, "Hemophagocytic lymphohistiocytosis in adults," Hematology/Oncology Clinics of North America, vol. 29, no. 5, pp. 915-925, 2015.

[2] S. Gupta and S. Weitzman, "Primary and secondary hemophagocytic lymphohistiocytosis: clinical features, pathogenesis and therapy," Expert Review of Clinical Immunology, vol. 6, no. 1, pp. 137-154, 2010.

[3] M. B. Jordan, C. E. Allen, S. Weitzman, A. H. Filipovich, and K. L. Mcclain, "How I treat hemophagocytic lymphohistiocytosis," Blood, vol. 118, no. 15, pp. 4041-4052, 2011.

[4] A. M. Schram and N. Berliner, "How I treat hemophagocytic lymphohistiocytosis in the adult patient," Blood, vol. 125, no. 19, pp. 2908-2914, 2015.

[5] P. La Rosée, "Treatment of hemophagocytic lymphohistiocytosis in adults," Hematology, vol. 2015, no. 1, pp. 190-196, 2015.

[6] F. Stephan, B. Thioliere, E. Verdy, and M. Tulliez, "Role of hemophagocytic histiocytosis in the etiology of 
thrombocytopenia in patients with sepsis syndrome or septic shock," Clinical Infectious Diseases, vol. 25, no. 5, pp. 11591164, 1997.

[7] J. A. Carcillo, D. W. Simon, and B. S. Podd, "How we manage hyperferritinemic sepsis-related multiple organ dysfunction syndrome/macrophage activation syndrome/secondary hemophagocytic lymphohistiocytosis histiocytosis," Pediatric Critical Care Medicine, vol. 16, no. 6, pp. 598-600, 2015.

[8] I. Voskoboinik and J. A. Trapani, "Perforinopathy: a spectrum of human immune disease caused by defective perforin delivery or function," Frontiers in Immunology, vol. 4, p. 441, 2013.

[9] R. A. Raschke and R. Garcia-Orr, "Hemophagocytic lymphohistiocytosis: a potentially underrecognized association with systemic inflammatory response syndrome, severe sepsis, and septic shock in adults," Chest, vol. 140, no. 4, pp. 933-938, 2011.

[10] R. J. Risdall, R. W. McKenna, and M. E. Nesbit, "Virusassociated hemophagocytic syndrome a benign histiocytic proliferation distinct from malignant histiocytosis," Cancer, vol. 40, pp. 993-1002, 1979.

[11] S. Imashuku, K. Kuriyama, R. Sakai et al., "Treatment of Epstein-Barr virus-associated hemophagocytic lymphohistiocytosis (EBV-HLH) in young adults: A report from the HLH studyl center," Medical and Pediatric Oncology, vol. 41, no. 2, pp. 103-109, 2003.

[12] M. George, "Hemophagocytic lymphohistiocytosis: review of etiologies and management," Journal of Blood Medicine, vol. 5, pp. 69-86, 2014.

[13] J.-I. Henter, M. Aricò, R. M. Egeler et al., "HLH-94: a treatment protocol for hemophagocytic lymphohistiocytosis," Medical and Pediatric Oncology, vol. 28, no. 5, pp. 342-347, 1997.

[14] J. I. Henter, A. Horne, M. Aricó et al., "HLH-2004: diagnostic and therapeutic guidelines for hemophagocytic lymphohistiocytosis," Pediatric Blood \& Cancer, vol. 48, no. 2, pp. 124-131, 2007.

[15] S. Imashuku, K. Kuriyama, T. Teramura et al., "Requirement for etoposide in the treatment of Epstein-Barr virus-associated hemophagocytic lymphohistiocytosis," Journal of Clinical Oncology, vol. 19, no. 10, pp. 2665-2673, 2001.

[16] C. Askin, A. Burris, C. Layman, B. Haney, and J. Hall, "A case of spontaneously improving secondary hemophagocytic lymphohistiocytosis in an adult associated with T-cell histiocyte-rich large B-cell lymphoma," Case Reports in Oncological Medicine, vol. 2018, Article ID 8069182, 5 pages, 2018.

[17] K. Devitt, J. Cerny, B. Switzer et al., "Hemophagocytic lymphohistiocytosis secondary to T-cell/histiocyte-rich large B-cell lymphoma," Leukemia Research Reports, vol. 3, no. 2, pp. 42-45, 2014.

[18] L. Castillo and J. Carcillo, "Secondary hemophagocytic lymphohistiocytosis and severe sepsis/systemic inflammatory response syndrome/multiorgan dysfunction syndrome/macrophage activation syndrome share common intermediate phenotypes on a spectrum of inflammation," Pediatric Critical Care Medicine, vol. 10, no. 3, pp. 387-392, 2009. 


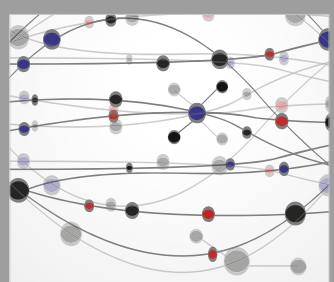

The Scientific World Journal
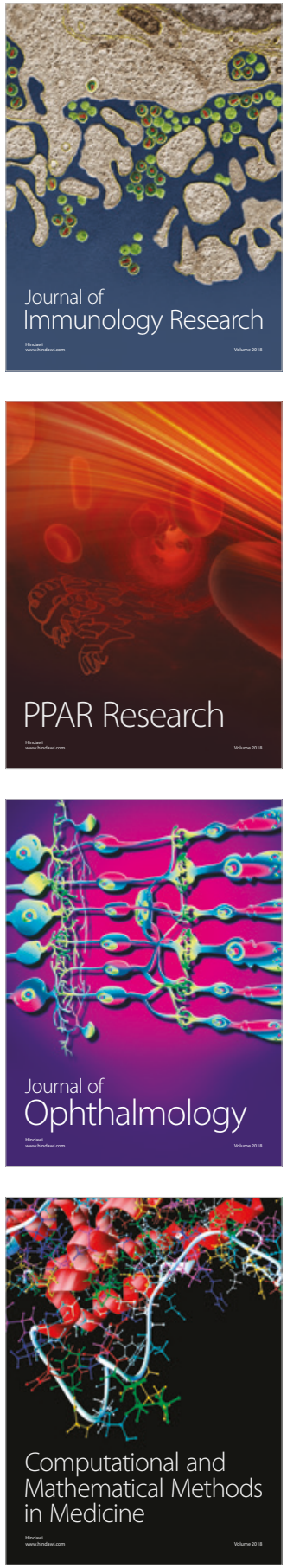

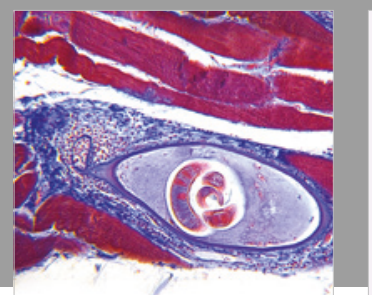

Gastroenterology Research and Practice

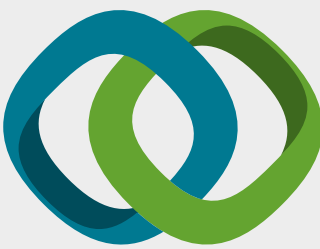

\section{Hindawi}

Submit your manuscripts at

www.hindawi.com
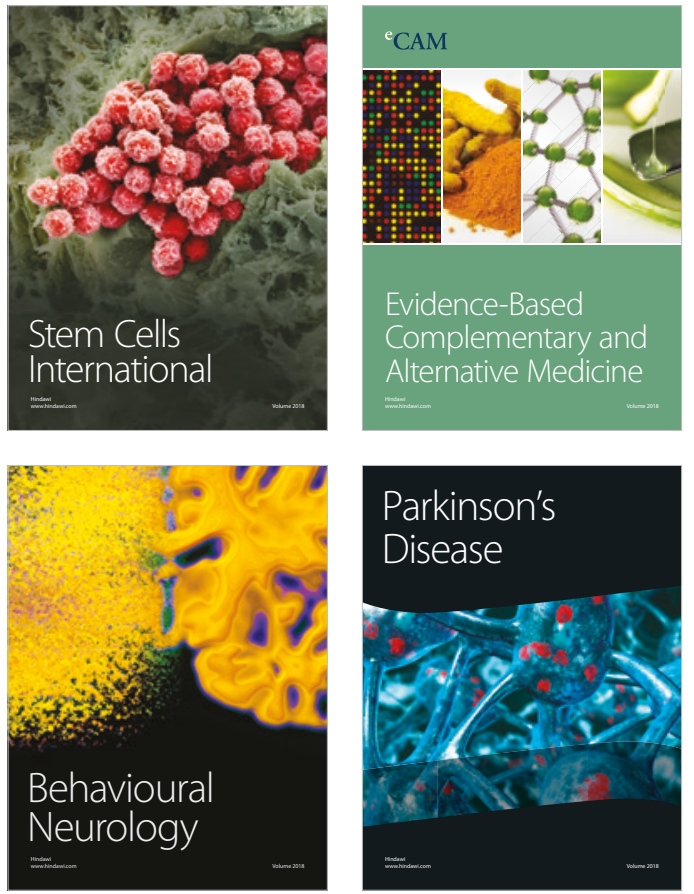

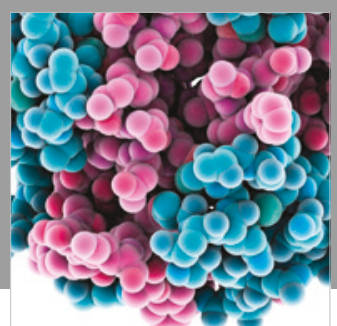

ournal of

Diabetes Research

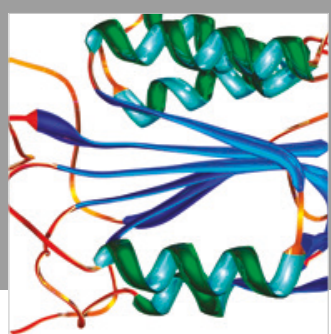

Disease Markers
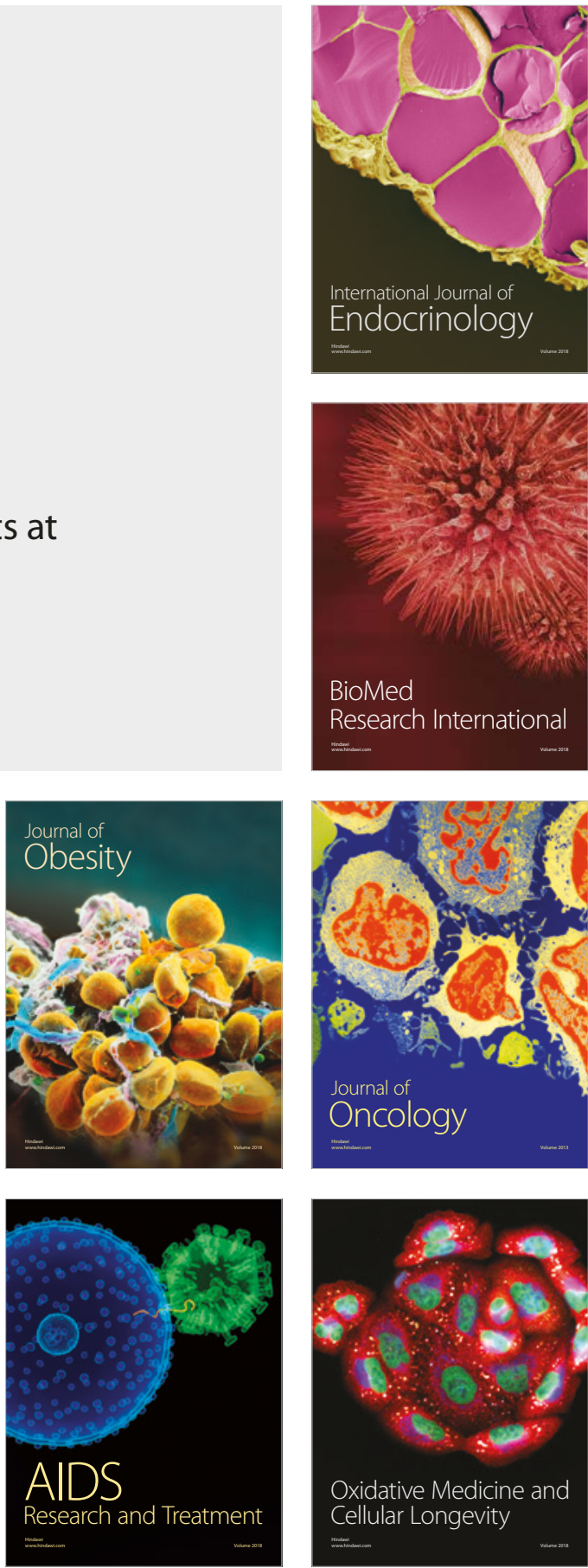